\title{
What Can the Temporal Structure of Auditory Perception Tell Us about Musical "Timelessness"?
}

\author{
Jason D. K. Noble
}

NOTE: The examples for the (text-only) PDF version of this item are available online at: http://www.mtosmt.org/issues/mto.18.24.3/mto.18.24.3.noble.php

KEYWORDS: timelessness, time, temporality, music, auditory perception, induction, cognition, information, embodiment, temporal structure, Truax, Ligeti, Crumb, Reich, Tenney, Messiaen, Grisey

ABSTRACT: "Timelessness" is an area of intense interest for many composers and authors interested in 20th- and 21st-century music, but it is not always clear exactly what the term denotes. In particular, the distinction between the induction of timelessness (the listener's subjective experience of time is altered or suspended by music) and the perception of timelessness (the listener recognizes that the music expresses altered or suspended time) has yet to be clarified. This paper argues that, while experiences of timelessness may be induced by a wide variety of musics and are not necessarily contingent on specific musical qualities, the perception of musical timelessness involves relationships between music's temporal organization and the temporal structure of auditory perception. Of particular interest are segmentation, sequence, pulse, meter, and repetition. Music whose temporal organization optimizes human information processing and embodiment expresses "human time," and music whose temporal organization subverts or exceeds human information processing and embodiment points outside of human time, to timelessness. This hypothesis is illustrated with examples from the 20th-century repertoire by Truax, Ligeti, Crumb, Reich, Tenney, Messiaen, and Grisey, music that has been associated with timelessness.

DOI: $10.30535 / \mathrm{mto} .24 .3 .5$

Received November 2017

Volume 24, Number 3, September 2018

Copyright $\odot 2018$ Society for Music Theory

[1] What can it mean to speak of music, the temporal art par excellence, as "timeless"? Composers and theorists of the 20th and 21st century speak with fascination about a radical transformation of time in certain strains of post-tonal music, describing the "spatialization of time" (Hasty 1997, 297), "a real dissociation from the past and future" (Kramer 1988, 382), and "an eternity that is present in every moment" (Stockhausen 1963; quoted in Heikenheimo 1972, 120-21). While discrepancies between time subjectively experienced and time objectively quantified are widely recognized-our estimations of duration and of the "speed" of the "passage" of time are notoriously inaccurate and contingent on a variety of contextual factors (Kramer 1988, 369) - the discourse of musical 
timelessness seems to go far beyond quantitative comparisons of phenomenological assessment and chronometric measurement. Authors frequently imply a complete withdrawal from the experience of time, or even an annihilation of time itself.

[2] Composers and theorists are not alone in their interest in musical timelessness. Listeners around the world describe similar experiences in response to music of many kinds, claiming they "experience an entirely different state of being" (Sandstrom and Russo 2011, 227), "lose the sense of time passing [and] feel transported out of quotidian space" (Becker 2004, 25), and experience "sensations of an existential or transcendent nature" (Margulis 2013, 66-67). Such experiences reportedly arise in a wide variety of listening contexts: they may be linked with music in religious ceremonies, or in "highway hypnosis" while driving; they may be elicited by special personal memories associated with a particular song, or by the impression of hearing an amazing new work for the first time; they may be associated with vigorous physical activity, as in dancing, or with profound physical relaxation, as in meditation. Experiences of timelessness, often described in terms of musical absorption (Sandstrom and Russo 2011), deep listening (Oliveros 2005), or the trance state (Rouget 1980), have been associated with the "slain in the spirit" ecstasy of American Pentecostal worshippers singing hymn choruses (Becker 2004, 97-100); with Tibetan chant and other religious chanting traditions (Becker 2004, 42); with Italian "tarantism," in which a spiderbitten person attempts to "dance off" the poison (Becker 2004, 34-37); with clubs and raves where the musical genre called "trance" originated (Sylvan 2005); with lifelong fans of rock musicians finally hearing their favorite songs performed live for the first time; and with the dedicated listening of new music enthusiasts at contemporary concerts. The musics through which such experiences arise may be vocal, instrumental, or electroacoustic, tonal or atonal, metric or ametric, loud and rhythmic, or soft and meditative. Since the experience of the musical "eternal now moment" (Hasty 1997, 296) may be induced in such diverse cases, it is unclear how timelessness may relate to specific musical properties. Becker claims that "the relationship between music and trance is neither causal or deterministic....given the right cultural expectations, any kind of music, vocal or instrumental, can be associated with trance" (2004, 25-26; see also Rouget 1980). And yet, the passionate comments of many authors and composers clearly imply that they believe a special relationship exists between timelessness and particular types of music. Is timelessness exclusively a property of a person's subjective experience of listening, or is there any meaningful sense in which it may be in the music?

[3] This question invokes the famous semiological tripartition of Molino (1975) and Nattiez (1990), which distinguishes the poietic level of sign production, the immanent level of the material trace of the sign, and the esthesic level of sign interpretation. Owing to differences in subjective listening contexts, attention, enculturation, and so forth, listeners may vary widely in their (esthesic) responses to music, including their experiences of musical timelessness: a piece by Ligeti may induce a transcendental experience of suspended time in one listener, while in another it may induce boredom and irritation; on another occasion, the same two listeners may have opposite experiences listening to a song by The Doors; and in a different situation or distracted state of mind, both pieces of music may fail to induce a timeless experience in either listener. The esthesics of musical timelessness is a fascinating subject, but because it involves so many variables and so much intersubjective variation, I believe it is best approached through the kind of empirical study of listener responses that Kristina Knowles (2016) has recently begun to pursue, which, while tremendously valuable, is beyond the scope of the present study. On the other hand, exploring the poietic side risks leading us down the rabbit hole of reconstructing intentionalities, attempting to explain one trace (for example, a composer's scores) in terms of others (e.g., their writings and interviews); all the while the composer's "true intentions" remain, as ever, obscured by the problem of other minds. While I am inclined to believe that the composers discussed in this paper sometimes deliberately attempt to achieve expressions of timelessness in their music, it is not my goal to reconstruct their poietic thought processes or compositional methods. Rather, I want to focus on the immanent properties of the musical trace. If there is a meaningful link between the music discussed in this paper and the concept of timelessness invoked by its composers and theorists, can this link be explained in terms of observable features of the music without deferring to our epistemologically shaky understanding of composers' intentions or the notoriously inconsistent responses of listeners? 
[4] In bracketing individual esthesic responses from this discussion of musical timelessness, I am not excluding questions of perception altogether. Quite the contrary: auditory perception - its temporal structure in particular - is the foundation of this analysis. As the emerging field of music perception and cognition has demonstrated in recent decades, many aspects of musical experience display significant statistical regularity across subjects. I would like to suggest that some findings pertaining to the temporal structure of auditory perception (for instance, the range of tempi within which pulse and meter may be perceived, the qualitative differences in our perception of periodic phenomena in different frequency regions, and so forth) may explain a great deal about musical timelessness. We can bracket the question of whether or not a given musical example induces a state of timelessness in any given listener (or hearing), and instead ask how the temporal organization of the music aligns with the scale and structure of optimal human auditory information processing and embodiment, which will henceforth be called human time.

[5] Human time is related to what Arnie Cox (2016) calls Mimetic Motor Action (MMA) and Mimetic Motor Imagery (MMI). It encompasses the temporal scales and structures to which our cognitive processing and motor abilities are well-adapted, and in which we can participate gesturally or vicariously. Human time is defined by the time zones of biorhythms such as breathing, footsteps, chewing, and syllables of speech, which are characterized by "fuzzy" ranges of variation. We have a general sense of a "normal" walking pace (denoted by the musical tempo "andante'), a fast walking pace, a running pace, and a pace that exceeds human locomotion; similarly, breathing can be very fast or very slow, but after some (fuzzy, variable) threshold we pass into a pace that is too slow to correspond with human breathing. Most Western music is structured within time zones corresponding roughly with such human scales, offering pulses to which we can easily entrain, grouped in simple, repeating metrical patterns that facilitate cognitive processing of more complex surface rhythms. Notes gravitate strongly towards durations that function as optimal perceptual units, and are grouped into phrases that provide meaningful and digestible segmentations of longer timespans. Such structuring facilitates performance and comprehension by humans, and it is pervasive in the history of Western music: as Justin London notes, "the presence of rhythmic regularity ... is normative or prototypical for most styles and genres of music ... [Entrainment] affords both the perception of motion as well as our ability to move with the music, either in our aural imagination or in fact" $(2009,51-52)$. Petr Janata et al. observe the importance of "groove" in most Western music, to which we readily and enthusiastically entrain: "the engagement of people's motor systems while listening to music is common-place and seems to have an almost automatic, irresistible quality to it" $(2012,54)$. Cox remarks that "the history of Western music, classical and vernacular, has been dominated by music that is either easily singable, or easily danceable, or both. . . e easily danceable music has a regular beat, with relatively simple and regular rhythms, at a tempo that affords efficient whole-body mimetic movements" $(2016,47)$. When western art music pushes the upper limits of performability with extremely rapid deployment of notes that challenge our ability to process or imagine ourselves executing, as for instance in unmeasured cadenza passages in virtuosic piano music, our grounding in human time may be dazzled or disrupted because the music verges on the "superhuman." At the other end, the drones and extremely long resonances of gongs that accompany meditative practices in many non-Western cultures extend into time spans that exceed the normal limits of our cognition and motor activity, bringing us "out of time." And if, as is sometimes the case in contemporary music, rhythm attains a degree of hypercomplexity so extreme as to exceed our ability to parse and entrain, then its rhythmic elements assimilate into a "gross morphology" whose fine structure is, for us, impenetrable, because "our perceptual and cognitive limitations block our direct access of such complex structural details" (London 2009, 65). In situations such as these, most people are no longer able to actively or imaginatively participate in the same way that they do in more normative musical experiences, but only to observe, perhaps in awe or contemplation, the unfolding of events or processes too fast, extended, or complex to comprehend or reproduce. Human time is thus exceeded or subverted through the temporal structure of the music, which may then be perceived as a sign for a negation of or alternative to human time: in other words, for us, timelessness. ${ }^{(1)}$

[6] As mentioned above, it is crucial to recognize the difference between music being perceived as a sign of timelessness and music inducing an experience of timelessness. Perception (as I am using the term here) relates more directly than induction to properties of the musical trace, and to general 
properties of audition. The distinction between perception and induction is familiar from research on musical emotion: ${ }^{(2)}$ we may perceive that music expresses happiness without actually feeling happy in response to it (for example, a chipper commercial jingle may be irritating), and music may induce happy feelings in us even if we believe the music to express a different emotion (for example, a sad song may remind us of a loved one). With respect to temporality (conceived here as a state of existing within or having some relation to time, real or virtual ${ }^{(3)}$ ), the perceptioninduction distinction is familiar from film techniques such as slow motion, time lapse, nonlinear plot, and montage, which are understood to signify temporal fictions with scales or structures of time that deliberately depart from ordinary human experience. Modern audiences understand that the man-ape in 2001: A Space Odyssey does not literally begin moving more slowly upon discovering the violent potential of tools, nor do the people in Koyaanisqatsi literally hurtle through the subway terminal at superhuman speeds; furthermore, audiences may appreciate the aesthetic effects and fictional significance of these slow motion and time lapse sequences while remaining within their own quotidian temporalities, without the induction of an altered state of time. Indeed, it may be from the differences between the temporality of the viewer and the alternate temporalities effected by these film techniques that they gain their artistic meanings. It is undoubtedly true that viewers sometimes lose track of time while watching film, but many a montage goes by without disrupting the viewer's subjective experience of time. As I will try to show, the case may be similar for musical timelessness: it may be possible to perceive a piece of music as signifying timelessness, whether or not an experience of timelessness is subjectively induced. I believe this happens when music's temporal organization exceeds or subverts temporal thresholds that characterize human time. To demonstrate this, I will first review some important concepts relating to time, timelessness, and temporality, then review relevant empirical findings on the temporal structure of human auditory perception, and finally explore connections between the two with reference to a number of case studies of 20th-century compositions.

[7] Most of the extant empirical literature on musical time focuses on the perception of beat, meter, and tempo in traditional western music or artificial stimuli. ${ }^{(4)}$ Within the field of music perception and cognition, there has been a relative paucity of attention to 20th- and 21st- century music in general, and to temporal experience in this music in particular (with a few exceptions, including Knowles 2016; Luchese 2010; London 2009). Some interesting works have addressed time and temporality from theoretical or musicological and ethnomusicological perspectives, ${ }^{(5)}$ but these have rarely discussed the temporal structure of auditory perception. As Knowles points out, "Scholarship on music and time tends to oscillate between the semiological representations of time within the musical work that are situated within compositional choices and cultural constructs, and perceptual approaches that highlight how time may be perceived within music" $(2016,67)$. I aim to begin bridging the gap between these two approaches by analyzing the musical trace on the basis of empirical findings. I will not introduce new empirical evidence, but will apply to the question of musical timelessness some illuminating ideas from the field of music perception and cognition.

[8] When approaching a subject as vast, daunting, and studied as time, one has no choice but to be selective about which sources to consult. Since my goal is to demonstrate coherence between the temporal structure of auditory perception and musical expressions of timelessness, I will focus on empirical studies of temporal experience from a psychological and phenomenological point of view, with reference to some theoretical and philosophical sources. However, I acknowledge with gratitude the important work that has been done by thinkers such as Bergson, Einstein, Husserl, McTaggart, Heidegger, Kant, Newton, and countless others in dozens of disciplines over thousands of years. I also acknowledge that that the data upon which most of the cited sources draw was collected in Western countries and therefore may be biased by Western enculturation; this is an endemic issue in perceptual studies in many disciplines (Henrich, Heine, and Norenzayan 2010). While there may be reason to speculate that some properties of auditory information processing and musical embodiment are generalizable to broader populations, for others (e.g., entrainment to complex rhythms) there is strong reason to suspect that cultural differences are considerable and may result in very different outcomes between different populations. As such, the reported findings should be understood only in the context of Western contemporary musical culture. May 
future studies explore broader repertoires and populations, and confirm or refute the generalizability of the ideas discussed here.

\section{Time, Timelessness, Temporality}

[9] "What then is time?" St. Augustine famously asked, and his answer - "If no one asks me, I know; if I wish to explain it to one that asketh, I know not" (Augustine 1860, 313; quoted in Fraser $1975,25)$ - still resonates with many who contemplate this most elusive of subjects. Benedict Taylor observes that "[time] may be approached from differing philosophical, theological, physicist and psychological perspectives, and even within each discipline (let alone between them) there is no overall consensus as to a correct viewpoint" $(2010,257)$. Thomas Reiner remarks that the study of time "abounds with problems, contradictions, and controversies; and this is in spite of, and at the same time because of, the tremendous amount of research in this area" $(2000,183)$. In everyday speech, our concept of time is steeped in metaphor, especially metaphors involving space and motion. Cox describes two pervasive ways of describing our relation to time: motion through time, in which "one's own motion toward the future implies a kind of temporal landscape through which one moves," and motion of time, in which "we stand in the present as future events approach us" $(2016,116)$. He goes on to show that many temporal terms-before, after, series, sequence, previous, prior, next - are etymologically spatial, and that although "we do indeed have a few terms for time that are not necessarily tied to space and motion ... most of our temporal concepts nevertheless are borrowed from literal spatiotemporal experience" (119-21). Further complicating the matter are the frequently-noted discrepancies between time as measured (variously denoted as chronological time, absolute time, clock time, ordinary time, ontological time, chronometric time, etc.), and time as lived (psychological time, phenomenological time, experiential time, subjective time, gestural time, integral time, etc.) (Kramer 1988, 9). The former is classically presumed to be ubiquitous, unidirectional, linear, and ever-constant in its "pace" (Lochhead 1982, 51), and the latter is presumed to fluctuate, sometimes seeming to go faster, sometimes slower, and perhaps sometimes even to stop altogether. But as Knowles points out, "the notion of an objective Time against which we can relate subjective fluctuations of experienced time ... falls into the same logical trap. In order to know that there is a time that is flowing equably, it is necessary to have another time, that is, a hypertime, that can measure the first time . . . this hypertime would then need a hyper-hypertime to measure $i t$, and so on into an infinite and vicious regress" $(2016,65)$.

[10] I offer these few anecdotes - which do not even begin to approach the perspectives of other disciplines such as physics and neuroscience-merely as a brief sketch of the scale of the problem of defining time. It is clearly beyond the scope of this paper to address this issue comprehensively. But I trust that, like St. Augustine when not asked to explain, we have a basic-if imprecise-sense of what time is, and need not halt all discussion on the matter for lack of an exact definition. Very coarsely, in this paper, time is conceived as a framework within which phenomena (in the most general sense) may have extension (duration) as well as relations to one another (e.g., simultaneity, succession, before, after) and to an experiencing subject (e.g., past, present, future). I am inclined to agree with the hypothesis that time is an inference rather than a percept, since our senses respond to energy or matter (of which time is neither) and since, for all our conceptualizing, there is no sensation or entity in our perception that corresponds directly with the concept of time. J. J. Gibson made this point in his article "Events are Perceivable but Time is Not," in which he describes time as an intellectual achievement "abstracted from the percepts of events and surfaces" $(1975,299)$. Reiner reiterated this idea years later: "if stimuli are characterized as types of physical energy to which sense receptors can respond, then sound qualifies as such a stimulus, whereas time does not. . . considering that inherent temporal properties do not constitute stimuli in their own right, time is not perceivable" (2000, 187-88); however, "one can speak of physical occurrences which possess temporal properties, and which allow for the inference of time" (23-24). Similarly, Cox observes that "to speak of the perception of time and of temporal motion is usually to speak loosely. What we perceive are states, changes of state (state-change), and differences between states (state-difference), along with the temporality in our experience of these perceptions (yet-to-occur, occurring, and having-occurred, corresponding to anticipation, presence, and memory)" (2016, 133). As such, in this paper I will avoid the term time perception and speak instead of the subjective 
experience of time. Of particular interest to this study are interactions between chronometric proportions (of the musical trace) and subjective experiences, especially those cases in which quantitative differences in the former give rise to qualitative differences in the latter.

[11] Musical timelessness can mean a great many things. J. T. Fraser has noted that time is colloquially understood in terms of the normal experience of people in full awareness of themselves, while all experiences that deviate from this are lumped together under timelessness $(1975,305)$. Used in this blanket way, the term can seem to gloss coarsely over important distinctions in both general and specifically musical senses. Many authors have described the difference between two times in which we live simultaneously: one cyclical, characterized by periodic processes in nature such as breathing, days, seasons, and the circle of life; the other historical, characterized by incessant, irreversible succession. It seems to be the latter sense that most composers and authors mean to negate when they speak of timelessness (sometimes by invoking the former). Fraser offers a hierarchy of temporalities ranging from atemporality, in which the only possible relation between events is simultaneity, to nootemporality, an advanced perspective of time requiring an intelligent subject capable of long-range knowledge of the past and future as well as complex sequential relations among events, with intermediate stages called prototemporality, eotemporality, and biotemporality. Jonathan Kramer adapted Fraser's categories to a corresponding list of specifically musical temporalities: vertical time, moment time, multiply-directed linear time, nondirected linear time, and linear time (1988, 395-96). Some music theorists distinguish musical temporalities based on their formal functions: for example, lyric time corresponds with melodic clarity and thematic exposition, and is associated with the present, while narrative time corresponds with more complex developmental structures of phrasing, harmony, and rhythm, and is associated with the past; furthermore, harmonic structures have been characterized as extending the present, anticipating the future, and recalling the past (Klein 2004, 37-39; Monelle 2000, 11521).

[12] Some composers devise idiosyncratic temporalities that may relate to specific images or concepts. For example, in the preface to his Quatuor Pour la Fin du Temps (1941), Olivier Messiaen quotes the passage from the Revelation of St. John depicting the end of time, and differentiates a number of contrasting temporalities in the composition's eight movements. In their titles and preface notes, the movements address subjects including eternity, immortality, the end of time, and opposite of time (1942, preface). Taylor remarks, "Messiaen's music is actually concerned with the expression and defamiliarisation of different senses of time, rather than the impossible search for eternity" (2010, 270). Diane Luchese says that Messiaen's music "engages our imagination of the spiritual through its evocative ambiance, which may be interpreted as a sonic metaphor for eternity" (2010,180). Messiaen's student Gérard Grisey, in works such as Le Temps et l'Écume (1989) and Vortex Temporum (1994-96), distinguishes between "the time of humans (the time of language and breathing), the time of whales (the spectral time of sleep rhythms), and the time of birds or insects (extremely contracted time where contours fade)" (Grisey 1996; quoted in Hervé 2001, 19). He describes "real" musical time as "a place of exchange and coincidence between an infinite number of different times" (Grisey 1987, 274).

[13] Do all of these different categories of time, temporality, and timelessness have perceptual reality? Do the semiotic dimensions of time described by composers and theorists cross the gulf into the experiences of listeners? These are interesting questions that merit future theoretical and empirical research. However, for the purposes of this paper, I will provisionally accept the simple opposition of human time and timelessness, in the interest of demonstrating how timelessness may relate to musical organization.

\section{Temporal Fiction, Information Processing, and Embodiment}

[14] As briefly noted above, music may be thought of as creating temporal fictions. Raymond Monelle states that in addition to being structured within time, music may also "mean" or "signify" time, and that we must therefore distinguish between the temporality of the signifier and the temporality of the signified $(2000,82-83)$. Cox describes many of the metaphorical aspects of musical experiences in terms of fiction, such as "crunchy" dissonances and "iridescent mist" in a 
piece by Debussy, which he likens to "facts and truths within fictional worlds" $(2016,154)$. I suggest that music can create fictional worlds of timelessness, and that it may do so through music's temporal organization. Each work of art presents itself as a kind of self-contained universe, abiding by internal rules defined in fictional contradistinction to reality-what Theodor Adorno called a "determinate negation" $(2006,20)$. In music, this fiction is specifically temporal, defined by the deployment of sounds in time, with the temporal proportions and relations of musical events taken as proxies or signs of the temporalities of their self-contained worlds. Christopher Hasty points out that we customarily "identify time with the process of change ... mistak[ing] time for events, forgetting that it is events that occur quickly and not time itself" $(1986,60)$. This identification has important consequences for the way music may signify time, implying that changes in the temporal scales and structures of musical events may be perceived as changes of time itself (or of the scale or perspective from which time is experienced). To again take examples from film: when, in the middle of intense and fast-paced action sequences in films such as The Matrix or 300, motion suddenly slows to a fraction of its original speed and the characters appear to be floating, enculturated audiences understand that the implication is not that the depicted gestures themselves have slowed in this way, but that the time scale from which they are viewed has "zoomed in." This is the sort of impression I intend to express by the term temporal fiction. Analogous examples may be found in pieces such as Grisey's Espaces Acoustiques, in which the composer consciously and deliberately creates temporal “dilations" (Chen 2010, 29).

[15] Temporal fictions in music may conform closely to the scales and structures that characterize optimal human information processing and embodiment, or they may depart from them in a variety of ways, just as the fictional universe of a film may be very close to the world we know or may be radically different. Creators of music may deploy information at an easily digestible pace, they may mete it out very slowly such that details that might otherwise seem trivial become major musical events, or they may overwhelm the listener with so much that it becomes difficult or impossible to process it all, resulting in the fusion of many sound events or sources into a single auditory gestalt. In Bob Snyder's terms, they may make music that is well suited to memorization, or they may adopt low- or high-information strategies of "memory sabotage" $(2000,234-38)$. Of course, information processing is highly complex and affected by differences in attention, familiarity, contexts of interpretation, and so forth; ${ }^{(6)}$ yet in spite of this, there are considerable consistencies among listeners in their responses to at least some aspects of auditory information processing and embodiment.

[16] One might wonder how to disentangle information processing from embodiment in analyzing our perceptions of temporal structures in music. This question is difficult to answer, because the time scales that characterize the grouping and parsing of information in the auditory system are often closely aligned with those that characterize our mimetic engagement with music. For example, the range of tempi in which we can perceive a beat (by synchronizing neural oscillations with environmental patterns, according to entrainment models; Grahn 2012) is also the range in which we can create a beat (for example, by tapping). When we hear a beat, "what is choreographed is not only auditory attention but also mimetic motor imagery and action (MMI and MMA)" (Cox 2016, 137). Similarly, the shortest time interval we can hear as an element of a rhythmic figure is the same as the shortest time interval we can produce as an element of a rhythmic figure (London 2004, 27). Information processing and embodiment require separate terms because they involve different physiological structures and functions - the former involving the peripheral and central auditory systems, the latter involving the musculoskeletal system and conscious awareness or imaginationbut since the temporal structures relevant to this discussion are for the most part homologous between them, in this essay they will be treated in tandem with one another.

[17] Music "invites" or "resists" mimetic participation through (among other things) the durations of sound events, the presence or absence of meter, the complexity of surface rhythms, and so on.

As such, different temporal structures in music invite different kinds of mimetic behavior. It may be possible for music's temporal structure to seemingly defy embodiment, to "motivate a "disembodied" form of listening, insofar as mimetic participation is found to be attenuated" (Cox 2016, 205). However, as the following anecdote demonstrates, the mimetic invitation never disappears completely: 
In my teaching I used to use the beginning of Ligeti's Atmosphères as an example of music that does not invite mimetic participation. The opening mass of sound, a sustained "chord" of nearly indistinguishable pitches, is about as far from singable and danceable music as I can imagine. But then one of my students said, "I don't know, it kinda makes me want to do this," as she very, very slowly extended her arms and rotated her head and torso. (Cox 2016, 48)

The nonnormative mimetic experience offered by music of extremely extended sound events is in some ways similar to that offered by rhythmically "hyper-complex" music whose "details and isomorphisms cannot be part of our first-order experience" (London 2009, 58). In both scenarios, the temporal organization of the music exceeds or subverts one or more of the temporal thresholds of auditory perception (discussed in detail below). As a result, comprehension and mimetic participation may play a role by way of their attenuation or absence (Cox 2016, 209). The temporal fiction presented by the music in such cases deviates so far from our normal biorhythms, gestures, and interactions with the world that the music seems to negate and point outside of human timetowards timelessness.

\section{The Temporal Structure of Auditory Perception}

[18] The aspects of auditory information processing on which this discussion will focus are (1) duration, the perceptual present, and segmentation; (2) inter-onset interval and sequence; (3) periodicity in different frequency ranges; and (4) meter and hypermeter. Several decades of empirical research have revealed threshold values in these temporal parameters that determine our auditory representations with respect to these categories. As noted above, their temporal proportions approximate the scales of familiar stimuli from human life such as speech, footsteps, chewing, and heartbeats: musical patterns with similar time scales activate the same motor areas of the brain (Margulis 2013, 66). These proportions also manifest in aspects of embodiment, including mimetic motor action, mimetic motor imagery, singability, and danceability. Larger auditory units, such as phrases and hypermetric groupings, correspond to other aspects of human activity and psychology, such as breath capacity, gestural execution, and the limits of the short-term memory (Snyder 2000, 85). There will always be intersubjective variation in perceptual matters such as these, but the trends and categories are very consistent even if the specific numbers vary from person to person: "while the precise value of a . . threshold may be affected by context, its general range and order of magnitude will not" (London 2004, 28). Other, more content-dependent aspects of temporal perception - (5) grouping and (6) repetition-are also highly relevant, but since they are characterized less by defined threshold values and rely more on contextual information processing, I will treat them separately later in the paper.

\section{Duration, the Perceptual Present and Segmentation}

[19] There are qualitative differences in our perceptual representations of quantitative differences in the durations of events (Lehman 2012,13). The shortest perceptions are about 100ms in duration. We are capable of responding perceptually to stimuli shorter than $100 \mathrm{~ms}$-indeed, much has been made of a supposed $50 \mathrm{~ms}$ threshold beneath which events fuse into a continuum and above which they may be perceived separately $(7)$ - but the minimum duration of their perceptual representation is about 100ms (Repp 2005, 971), and it is much harder to glean information from very short stimuli. At the other end, the maximum duration of a stimulus that can be contained within a single percept is usually about 3-5, corresponding to the average limits of short term memory (Snyder 2000, 50). This interval approximately defines the upper boundary of the perceptual present, a variable finite interval that serially adjusts to the contents of our attention. ${ }^{(8)}$ The notion of the perceptual present runs contrary to the intuition that the present is durationless in the same way that a mathematical point is unextended, but it accords with the Gestalt nature of our temporal experience: we perceive the world as a series of finite meaningful units, not as an infinitely divisible barrage of durationless sensibilia. It is not the case, for example, that we first perceive a series of instantaneous spectra and then retrospectively synthesize them into a musical note.

Rather, the musical note is given as present, and it may be retrospectively analyzed as an evolution of instantaneous spectra. 
[20] Auditory events of $100 \mathrm{~ms}$ to $5-7 \mathrm{~s}$ duration are in the

range that we can optimally segment or "chunk" because they can easily be represented as perceptually present, immediately available to the mind and requiring minimal cognitive effort to perceive in their entirety (Example 1). The vast majority of musical notes in traditional Western music fall within this range: David Huron reports from a corpus study of 52 instrumental and vocal works of J. S. Bach and the vocal lines from 38 songs by Stephen Foster (a total of 13,178 notes) that the average durations of notes were $0.22 \mathrm{~s}$ for instrumental and $0.38 \mathrm{~s}$ for vocal works, with only $3 \%$ of notes longer than 1 s in duration (Huron 2001, 26-27). We are, of course, capable of appreciating stimuli with durations longer than the perceptual present as units, and in some cases much longer, such as complete musical movements or works that may be minutes or even hours long; however, this requires additional cognitive resources such as memory and counting. If musical units such as notes, phrases, gestures, or sound-objects are timed within the window of the perceptual present, we process them with minimal effort, but if their durations extend beyond that window, a more deliberate act of cognitive synthesis is required. Additionally, we are also most sensitive to precise durations within the perceptual present, and become much less accurate in our estimations outside of this range (Lehman 2012, 14-15).

\section{Inter-Onset Interval and Sequence}

[21] Temporal relations between the onsets of events also qualitatively affect our perceptual representations. Think of a dripping tap: if the drips are close enough together in time, they sound like a continuous sequence of "drip. . .drip. . .drip," but if they are separated by more than a couple of seconds each, the sense of sequence disappears, each drip appears as isolated, and it becomes more difficult to accurately predict when the next drip will occur. As this example demonstrates, the durations of the intervals between the beginnings of successive events (Inter-Onset Intervals, or IOIs) determine the way we relate those events to one another. Auditory events separated by $2 \mathrm{~ms}$ or less are perceived as simultaneous, while events separated by 3 to $25 \mathrm{~ms}$ are perceived as successive but unordered (that is, the listener knows they are not simultaneous but cannot discern the order in which they appear) (Example 2). ${ }^{(9)}$ Ordered sequence perception becomes reliable for events with a minimum duration of about $100 \mathrm{~ms}$, which also happens to be the shortest duration that can be perceived or produced as an element of a rhythmic or metrical figure (London 2009, 48), the approximate minimum time for cortical processing of musical events, the fastest possible vocal articulation of rapidly repeated syllables, and the shortest perceptual duration regardless of sensory modality (London 2004, 29). In between, from about $25 \mathrm{~ms}$ to $100 \mathrm{~ms}$ IOI, sequence perception tends to be ambiguous. At the other end, beyond about 1500-1800ms IOI, sequence perception becomes difficult or impossible and we instead perceive events in isolation. This value also corresponds approximately with a number of other perceptual thresholds, including the ability to physically reproduce durations with accuracy (Repp 2005, 971), the limit of echoic or sensory memory, and the shift in synchronization strategy from anticipation to reaction (London 2004, 29-30). Jessica Grahn (2017) has observed that most human gestures also fall within this range, and that while it is possible to execute longer gestures, it becomes increasingly difficult to execute them gracefully when they are much longer than two seconds.

[22] Segmentation and sequences make it possible to cognitively process long durations of auditory information as organized series of smaller units. While we may think of a musical work of several minutes or hours as a single unit, it is typically segmented into many smaller units (e.g., notes) and sequences (e.g., melodies) as we are experiencing it, and represented as a whole only retrospectively. Durations that fall within the perceptual present, and IOIs in the range of ordered sequence perception, facilitate auditory information processing and embodiment, and characterize human time; durations and IOIs that fall outside of these ranges challenge information processing and embodiment, and point outside human time.

\section{Periodicity in Different Frequency Ranges}

[23] The auditory system responds in qualitatively different ways to periodic phenomena in different ranges of frequency. As noted above, rhythmic sequences can be reliably perceived and executed up to a maximum speed of about $100 \mathrm{~ms}$ IOI $(10 \mathrm{~Hz})$. For vibrations between about 20- 
$30 \mathrm{~Hz}$ and 4000-5000 Hz, we perceive clear pitch (Plack 2014, 118-19). Higher vibrations up to about $20,000 \mathrm{~Hz}$ cannot easily be resolved as pitch but can be heard as a kind of indiscriminate buzz, which can contribute to timbre when grouped with other frequencies. Note that between the top end of sequence perception (c. $10 \mathrm{~Hz}$ ) and the bottom end of pitch perception (c. $20 \mathrm{~Hz}$ ) is what Edward Large has called a "no-man's-land" (2015), a region from about too fast to be resolved as rhythm and too slow to be resolved as pitch (Example 3). Auditory experience in this range can be ambiguous, characterized by roughness and a kind of pseudo-continuity in which events are neither clearly integrated nor clearly segregated. Perhaps because of perceptual ambiguity and difficulty of production, sound events in this no-man's-land played little role in music until recently (with the exception of ornamental figures like trills and drumrolls ${ }^{(10)}$ ). However, this liminal region has been explored by musicians in the late 20th and early 21st century.

[24] In the sub-audio frequency range (c. $<20 \mathrm{~Hz}$ ), we can still be highly sensitive to periodic phenomena but their perceptual representations are very different than for higher frequencies. Of particular importance for music is our ability to perceive beat or pulse, which exists within a range of about 200-2000ms IOI (300-30 beats per minute, or BPM): the "beat zone" (London 2004, 31). The lower limit, 200ms IOI, is about twice the shortest value that can form part of a rhythmical unit. As noted above, patterns with IOIs longer than 1500-1800ms tend to lose their sense of sequential integration and segregate into perceptually isolated events. Maximum pulse salience occurs at around $600 \mathrm{~ms}$ IOI (100 BPM), a pace that listeners tend to judge as neither fast nor slow, dubbed the "indifference zone" (London 2004, 30-31; Fraisse 1963, 128). This corresponds roughly with average walking pace and heart rate, as well as the tempo subjects spontaneously choose when asked to tap at a comfortable pace. The indifference zone is highly characteristic of human time, right in the middle of the standard tempo range for Western music (approximately 67150 BPM) (London 2004, 109-10; Parncutt 1994, 437). Patterns with IOIs much shorter than 200ms tend to be perceived as subdivisions, and patterns with IOIs much longer than $1500 \mathrm{~ms}$ tend to be perceived as larger groupings, of underlying pulses that gravitate towards the indifference zone (Parncutt 1994, 454).

[25] While we do not have a sensory organ that responds tonotopically to frequencies in the beat zone (as the basilar membrane of the cochlea does to audio frequencies), we can and do entrain to pulses, as is evident every time we dance or tap along with the beat of a song. Researchers have explained this behavior in terms of a "neural resonance theory" (Henry 2016), which claims with growing evidence that neural oscillation patterns synchronize with environmental periodic phenomena within the beat zone after just a couple of cycles and continue until after the periodic stimulation is terminated. One might wonder why we have developed this special entrainment for periodicities only up to a maximum IOI of c. $2 \mathrm{~s}$, when slower periodic phenomena such as breathing at a resting pace, ocean waves and tides, and diurnal cycles are also frequently encountered and may be important for us to anticipate. While the answer remains mysterious, the idiosyncratic perceptual relationship that we have with the beat zone makes it particularly significant in defining human time.

\section{Meter and Hypermeter}

[26] In addition to pulses within the beat zone, we are sensitive to higher-level patterns of accents within those pulses. Even when surface rhythms change continually such that there is no exactly repeating rhythmic pattern, meter - a repeating, abstract pattern of accented and unaccented pulses - can provide a cognitive framework that makes it easier to segment, process, remember, perform, encode, and reproduce rhythmic patterns (McAdams 2016). Meter also facilitates the synthesis of many successive events into larger temporal units. London considers meter to be a complex form of entrainment behavior, an "anticipatory schema that is the result of our inherent abilities to entrain to periodic stimuli in our environment" (London 2004, 11). Many studies have demonstrated listeners' strong proclivity for metrical entrainment: motion capture analysis reveals that dance movements can involve simultaneous entrainment to multiple metrical levels (Toivianen, Luck, and Thompson 2010, 67), and neurological analysis reveals that motor regions of the brain are activated in response to musical meter even when we do not physically move along with it (Chen 2008, 101). 
[27] Meter is predicated on a fundamental pulse or tactus which is created by the proximal recreation of a durational span (Knowles 2016, 100), grouped into repeating patterns of accents, with shorter values interpreted as subdivisions of the tactus and larger groupings interpreted as composite or hypermetric assemblages of metrical units (Huron 2006, 179). Hypermetric assemblages may exist at a variety of hierarchical levels. In accordance with what Huron calls the "binary default in Western meter perception" (Huron 2006, 195), by far the most common groupings of metrical beats, subdivisions of beats, and hypermetric groupings are binary or "powers of two" relations. A typical example would be a piece with four quarter-note beats in a bar, each of which subdivides into two eighth-notes, with phrases that are four bars long. The second most common scenario is groups of three (three beats, subdivisions of three, three-bar phrases). Much less common is music organized with more complex numerical relations (for example, "asymmetrical" meters, subdivisions, and phrases of five or seven units). As with beat perception, the temporal range within which we can perceive metrical groupings is finite. Meter by definition involves grouping of more than one component periodicity, and its temporal existence region ranges from a binary grouping of the shortest possible rhythmic unit $(2 \times 100 \mathrm{~ms}=200 \mathrm{~ms})$ to a compound grouping of the longest possible pulse $(3 \times 2 s=6 s)$. Perhaps not coincidentally, this range is roughly coterminous with the boundaries of the perceptual present (London 2004, 30-31).

\section{Summary}

[28] Entrainment facilitated by rhythmic regularity is "normative or prototypical for most styles and genres of music," and is so important in musical experience that the sense of motion it affords, London claims, is implicit in the very idea of music $(2009,51)$. The comprehension and mimetic engagement afforded by entrainment are optimized in human time: sound events are segmented into easily digestible units and connected in easily perceptible sequences, all musical strata are synchronized to a common periodic pulse within the beat zone, and simple metrical patterns provide cognitive frameworks by which to process more complex surface rhythms. In terms of specific temporal values, auditory events are most easily appreciated in the range of $100 \mathrm{~ms}$ to $5-7 \mathrm{~s}$ in duration - within the temporal window known as the perceptual present-and the vast majority of perceptual units (e.g., notes, phrases) in Western music fall within this range. Events with IOIs less than $3 \mathrm{~ms}$ yield perceptual simultaneity, 3-25ms an unordered sequence, 25-100ms perceptual ambiguity, $100-1800 \mathrm{~ms}$ reliable ordered sequence, and larger than 1800 perceptual isolation: the vast majority of IOIs in Western music fall within the range of optimal sequencing. Pitch perception corresponds with periodic sounds in the range from $20 \mathrm{~Hz}$ to $20 \mathrm{kHz}$, and pulse perception ranges from about 2000-200ms IOI (30-300 BPM) with maximal pulse salience around 600ms IOI (100 BPM). The vast majority of Western music is based on notes with fundamental frequencies in the range of maximal pitch salience and rhythms organized in relation to a pulse in the beat zone. The region between the upper limit of sequence perception $(10 \mathrm{~Hz})$ and the lower limit of pitch perception $(20 \mathrm{~Hz})$ is perceptually ambiguous, and has been avoided in Western music except in occasional ornamental functions. Metrical units may exist within the window of about $200 \mathrm{~ms}$ to $6 \mathrm{~s}$, and the vast majority of Western music is based on meters in this range.

[29] This list does not pretend to be exhaustive, and it leaves many questions unanswered. For instance, the roles of pitch, timbral, and dynamic information are not discussed in much detail here, and it is highly likely that all play a strong role in the expression of human time and its negation in timelessness. ${ }^{(11)}$ Nevertheless, temporal proportions and threshold values are important factors in relating musical structure to auditory perception, and they have been exploited in many fascinating ways by composers interested in timelessness.

\section{Subversion, Excess, and Timelessness}

[30] The foregoing discussion describes some of the factors in the normative Western musical expression of "being in time." It also provides a set of guidelines that may be subverted or exceeded if musicians seek to create alternative temporal fictions that challenge our ability to process information, or to mimetically engage. While there may be considerable differences between types of music that present such fictions, all deviate in some way from human time and thereby point to timelessness. Hasty said that the suppression of segmentation at some level is the 
decisive factor in achieving this goal $(1997,296)$, and indeed, subversive or excessive temporal structures impair in one way or another our ability to parse musical information into digestible chunks with orderly structural relations. Some of the ways composers have achieved this are summarized in the table shown in Example 4, along with musical examples.

\section{Ia. Segmentation Subverted: Barry Truax, Riverrun (1986) (1)}

"Granular synthesis is in a unique position to mediate between the micro and macro time worlds." (Truax 1999, 130)

[31] Barry Truax's Riverrun was the first piece created entirely with real-time granular synthesis (Hellmuth 2006, 190-91), a technique of electroacoustic composition in which large numbers of short sound events ("grains") are deployed stochastically to build "complex events from the seemingly trivial micro-level, enveloped quanta" (Truax 1999, 129). The perceptual triviality of the grains is a function of their attenuated durations: in the case of Riverrun, many grains (whose spectral content consists of sine tones or modulated sine tones) may be as short as $8 \mathrm{~ms}$ in duration (Truax 1988, 17-23; Hellmuth 2006, 191), well below the c. 100ms minimal duration for optimal segmentation. Thousands of such events may be deployed per second, distributed according to "tendency masks" (Truax 1999, 122) in geometrical patterns that are readily visible in a spectrogram of the piece (Example 5a). A zoomed-in perspective of a portion of this spectrograph visually conveys the granularity of the texture (Example $5 \mathbf{b}$ ).

[32] Another major composer associated with the development of granular synthesis, Curtis Roads, describes this level of "microsound" in terms of "hidden morphologies of elementary sound molecules" $(2001,40)$. The grains cannot serve the same perceptual function as notes in conventional music, precisely because their contracted temporal proportions are outside of the scale of the syntactical units of information processing in human time. Instead, the diminished subsegmental identities of the grains yield to a global listening perspective, focusing attention not on the patterns of distinct musical objects characteristic of human time, but on "dense agglomerations of particles [that] form swirling sound clouds whose shapes evolve over time" (Roads 2001, vii), suggestive of a different temporal order.

\section{Ib. Segmentation Exceeded: György Ligeti, Atmosphères (1961)}

"music as frozen time" (Ligeti 1988; quoted in Bauer 2004, 129)

[33] At the other end of the durational spectrum, musical sounds can exceed the boundaries of the perceptual present, sometimes vastly. Sounds that provide no cues denoting syntactical divisions for very long stretches of time disrupt the pace of the flow of information to which we are accustomed in daily life, and in normative Western musical experience. The suspension of change in those parameters that normatively support musical discourse-especially pitch and rhythmcreates a musical situation frequently described as "static," disrupting expectations about the structure and function of musical time, confronting the listener with a state of apparent changelessness for durations that may seem to stretch on indefinitely. This is perhaps the most intuitive musical expression of timelessness. A famous example is the opening chord of Ligeti's Atmosphères, which, at the notated tempo of 40 beats per minute, lasts 24 seconds before the first notated change (the morendo exit of the flutes, followed by similar exits from the bassoons, clarinets, horns, and violins) and over three times that long before the first "chord change" in $\mathrm{m}$. 13. As noted above, Cox (2016) considered this piece to invite an almost "disembodied" listening experience due to its extreme attenuation of mimetic invitation.

\section{IIa. Sequence subverted György Ligeti, Continuum (1967)}

"A microscopic, underwater world" (Ligeti 1983, 15)

[34] Recall that frequencies faster than c. $20-30 \mathrm{~Hz}$ (50-33ms IOI) are perceived as pitch, and frequencies slower than c. $10 \mathrm{~Hz}(100 \mathrm{~ms}$ IOI) are perceived as rhythmic sequences, but the region in between is ambiguous, neither completely fused nor completely segmented. In the late 20th 
century, perhaps emboldened by advancing performance practices and technologies, musicians began exploring the unique musical possibilities of this ambiguous region. An early example was Ligeti's Continuum (1967), in which the composer instructs the performer to play "extremely fast, so that the individual tones can hardly be perceived, but rather merge into a continuum" $(1970,1)$. As Amy Bauer notes, the effect is similar to trompe l'oeil, creating "a sense of stasis through extremely rapid activity" with the goal of creating "paradoxically continuous sound" (Bauer 2004, 129-30). Ligeti indicated that the tempo he had in mind was about 15-16 attacks per second (c. 67-63ms IOI), which he identified as the maximum that the harpsichord's mechanism would allow (Ligeti 1983, 22-23). When played at the desired tempo, the musical surface's flurry of notes challenges the human scale of auditory organization, occupying the liminal range in which we cannot quite resolve the notes as a sequence of discrete events, nor fuse them into a musical pitch.

[35] However, as all who have written about Continuum have remarked, the rate of attack and perceptual rhythm in this piece are not necessarily identical-a determination supported by experimental study (Douglas, Noble, and McAdams 2016). In places where the notes are arranged to create repeating patterns of between 2 and 8 notes, the apexes and/or nadirs of those patterns emerge as pulses in their own right, with periods proportionately longer than the overall rate of attack. For example, if the overall rate of attack is $65 \mathrm{~ms}$ IOI (beneath the range of optimal sequence perception), a 5-note pattern will produce a pulse of 325ms IOI (185 BPM), which falls within the beat zone. Much of the interest of Continuum proceeds from the tension between conflicting temporal zones-a surface rhythm whose extreme speed is self-cancelling in its subversion of our ability to perceive sequences (approaching a perceptual continuum), and higher-level patterns in a time zone that we can perceive emerging out of that texture (interrupting the continuum)

(Example 6). From the "timeless" flow of undifferentiated moto perpetuo appear figures and patterns that we recognize as "in time," which then disappear again into the relentless stream. This is a prime example of the kind of piece Knowles describes as "unmetered" from a macrocosmic perspective" $(2016,99)$. Although such examples are globally ametrical, "meter still plays a role. . . More often than not, metric cues may emerge in the musical surface that hint at possible meters, and in some cases, result in the emergence of a short-lived metrical structure. Such moments often provide an impulse in the energetics of the work, pushing the music forward and giving it momentum to continue" $(2016,99)$. Knowles goes on to describe meter itself "as a continuum, where music can not only be more or less metrical, but also almost metrical, and can flow fluidly from one state of metricality to another" $(2016,117)$.

\section{IIb. Sequence Exceeded: George Crumb, "III. Collapse of Time" (Echoes of Time and the River) (1967)}

"recurrences are echoes . . . time feels more circular than linear" (Kennedy 2002)

[36] Our ability to perceive musical sequences may be exceeded if sound events are separated far enough apart in time that they resist integration into an auditory stream. In such cases, the events instead appear as isolated phenomena in a discontinuous musical assemblage that resists "flow" within an auditory stream. Huron quantifies this in a principle of temporal continuity: "In order to evoke strong auditory streams . . intermittent sounds should be separated by no more than roughly $800 \mathrm{~ms}$ of silence in order to ensure the perception of continuity" (Huron 2001,12). To impede the perceptual formation of sequences with very long rests is to challenge that continuity.

[37] George Crumb does just that in the third movement of Echoes of Time and the River, "III. Collapse of Time." In the composer's program notes in the score, he writes that he wanted "to express in musical terms the various qualities of metaphysical and psychological time," and that the " "river of time" is an ancient metaphor which interprets time as a continuum without beginning or end" (Crumb 1968). The movement in which time "collapses" features brief gestures separated by rests as long as $7 \mathrm{~s}$ in duration. ${ }^{(12)}$ Although such pauses are measured by the performers, listeners have no way to predict how long they will last, contributing to a lack of continuity and predictability and creating an "atmospheric" quality in which long pauses interweave and interact with sound events: "rather than punctuating the sound fabric, the silence is a part of the fabric, the warp to the sonic weft" (Knowles 2016, 237). Knowles points out (and demonstrates empirically) that in such pauses "the listener's subjective experience of time may be 
so slow as to evoke conceptually the notion of timelessness, leading the listener to describe their experience of the piece as timeless" $(2016,23)$.

\section{IIIa. Pulse Subverted: Barry Truax, Riverrun (2) (1986)}

"a scale of composition ranging from human proportions to abstract" (Truax 1999, 123)

[38] Pulse is a very important aspect of human time, providing one of the strongest and most ubiquitous cues for entrainment and embodiment in traditional Western music. The absence of pulse is therefore a powerful marker for the musical expression of timelessness. It is of course possible never to introduce a perceptible pulse in the first place, as was the case in the example from Ligeti's Atmosphères above. Indeed, not only does Atmosphères avoid implications of pulse in its musical organization, but the composer explicitly prohibits pulse in the performance notes: "barlines in this piece are purely a means of synchronization ... There is no such thing as a beat in the sense of metrical pulsation ... the piece-with exception of a few specified places-should be played completely without accent" (1963). But the absence of pulse may be particularly salient if pulse is first established and then destroyed, perceptually foregrounding its subversion. This is the case in another section of Truax's Riverrun, in which grains are first deployed within narrow windows at 1-second intervals to clearly project a pulse in the beat zone, and then those windows gradually expand so that the stochastic distribution of grains pulls apart from the tactus. The sense of pulse gradually weakens until it dissolves altogether. Hellmuth describes this section as a "sharp edge in a virtual sea of contrasts" that "falls apart into a randomly complex texture," and notes that for Truax, the regularity was inspired by water dripping sounds and its dissolution transitions to a powerful fused image of a river $(2006,205)$. The implication of a shift in temporal and spatial orientations is clear in these comments, in the sound itself, and in the spectrograph of this section (Example 7).

IIIb. Pulse Exceeded: (i) Gérard Grisey, Le Temps et l'Écume (1988)

"a dilation of time" (Grisey 2008a, 153)

[39] Our capacity to perceive pulse can be exceeded when periodic sounds are spaced too widely to fall within the beat zone. In such cases, the listener is clearly aware of repetition, but it occupies a different perceptual order and serves a different function than a musical pulse. The opening of Gérard Grisey's Le Temps et l'Écume ("Time and Foam") presents such a situation. The piece, which is scored for instrumental ensemble and two DX7 synthesizers, opens with an ostinato of low C-F\# dyads in a synthetic timbre, repeating at intervals of about 5-6 seconds (well above the maximum IOI for pulse perception). The very gradual attack of this DX7 sound, as well as the very low dynamics, may also contribute to the absence of a perceptible pulse in spite of the obvious repetitiveness of the music. The piece's title refers to the ideas of astrophysicist John Wheeler, who compared the geometry of microscopic space-time to the surface of the ocean, appearing smooth when viewed from afar, but revealed to be in perpetual, turbulent change when viewed from a zoomed-in perspective (Baillet 2000, 185). Le Temps et l'Écume represents Grisey's first systematic use of the compositional concept of projecting the same object in different temporal scales (Baillet 2000, 185). The composer states that Le Temps et l'Écume "navigates between the time of whales, that of humans, and that of insects" (Grisey 2008a, 154), a theme to which he would return in Vortex Temporum (discussed below).

(ii) Steve Reich, Piano Phase (1967)

"recollection and anticipation seem to fall away" (Cox 2017, 417)

[40] Another way pulse perception can be exceeded is by superposing multiple musical strata with asynchronous pulses, causing interference between the pulses and preventing the listener from entraining to either pulse as an overall organizational framework for the music. Steve Reich's Piano Phase (1967) is a classic example (Example 8). In the 1960s, Reich created a number of pieces called "phase canons" in which two or more electronic or instrumental sound sources repeatedly iterate the same musical material with tempi that vary slightly with respect to one another, resulting in 
minutely asynchronous pulses with constantly changing phase relations. The process creates unstable rhythmic tension between the strata, which then resolves as the layers lock into a new phase relation with different emergent musical properties. In the first section of Piano Phase, player 1 repeats a 12-note cell with a perfectly metronomic tempo. Player 2 begins playing the same cell in synchronous unison and then, after a number of repetitions, accelerates very slightly. At this point the two are no longer enchained to a common tactus, and they move through a continuous series of complex phase relations until re-aligning in rhythmic synchrony with the pattern offset by one note. This process repeats until all possible alignments between the parts have been presented. A striking perceptual feature is the contrast between the phase-locked portions, which feel "in time," and the destabilizing dissolution of this alignment that brings the music "out of time." The shifts often seem categorical rather than continuous: just as we see the spectrum of a rainbow not as a true continuum but as bands of discrete colours (ROY G BIV) with fuzzy boundaries in between, we resolve the phase canon into discrete synchronous sections that slowly come apart into fuzzy regions of ambiguity before abruptly fusing back together in new (sometimes surprising) configurations. As Paul Epstein describes it:

At a certain point the irrational division of the beat caused by the echo presents a dizzying rhythmic complexity. When the voices are nearly $180^{\circ}$, or one half beat, out of phase, a doubling of the tempo is perceived; one has a momentary sense of stability, of a simplification of the irrational rhythmic relationship heard previously. This stage is very brief and is one of those events that seem to occur suddenly. The out-of-phase quality quickly returns and lasts until the new phase locks in. (1986, 498-99)

There is a revelatory quality to the emergence of a new phase lock and corresponding musical configuration from the perceptual instability of the preceding phase shift. And yet, since the identity of the musical cell is unambiguously at the fore of the musical surface the entire time, the music almost didactically emphasizes that new configurations were always implicit in its basic material: it is the perspective or orientation from which the musical object is perceived, and not the object itself, that gradually changes.

\section{IVa. Meter Subverted: Gérard Grisey, Vortex Temporum III (1994-96)}

“temporal distortions" (Baillet 2000, 227)

[41] Meter, the grouping of pulses into recurring accent patterns that provide a higher-order cognitive framework for processing musical information, may be subverted by eliminating the markers that imply a recurring pulse pattern (this is not necessarily the same as eliminating the pulse itself). A striking example is found in the third movement of Grisey's Vortex Temporum, the most complex movement in the work in terms of its temporal organization, and the one which most directly engages his ideas about the dilation and contraction of time. As noted above, its discourse is based on the contrast between what he calls the "time of humans" with the "time of whales" (dilated) and the "time of birds or insects" (contracted). This movement begins with a restatement of material with which the listener is already thoroughly familiar due to its ubiquitous presence in the opening section of the piece, a borrowed arpeggio figure from Ravel's Daphnis et Chloé. While the expressions of this figure undergo considerable transformations, a pulse at 120 BPM (close to the indifference zone) with unambiguously metrical patterns firmly establish human time. The temporal discourse of the movement comes to the fore when, at about 1:10, the arpeggio pattern is suddenly supplanted by sustained pitches in the winds and strings, reminiscent of the dilated time of movement II. Although the notated tempo and time signature do not change, all perceptual cues indicating metrical organization disappear, and since meter had been so perceptually prominent immediately prior, its absence is all the more conspicuous. Meter abruptly resumes with the return of the arpeggio pattern at rehearsal 6, c. 1:25.

[42] Later in the movement, at c. 4:30, contracted time makes its first appearance. The music here consists of very short, rapid gestures emphasizing noise and high pitches, separated by long pauses (from 3-8s) filled only by a pppp sustained high harmonic in the violin. Rapid doubletonguing in the flute, "virtuosissimo" ricochet in the viola, and tremolo gliss in the cello combine to deliver rates of attack that approach or reach the no-man's land between sequence and pitch. The 
aural effect is similar to a tape played at several times the normal speed-extremely compacted events, full of noise and high frequencies, delivered too fast to be intelligible. These gestures are very brief, and separated by enough non-segmented musical time to prevent a composite sense of pulse from emerging between them. This movement is an exposition of three alternating temporal fictions: one ideally suited to auditory information processing and embodiment with an unambiguous segmentation, sequencing, pulse, and meter; the others subverting the markers of metrical organization and adopting time scales that explicitly and deliberately point outside of human time.

IVb. Meter Exceeded: (i) James Tenney, KOAN (1971)

“some kind of perceptual revelation" (Tenney 1978; Lange 1999)

[43] Meter may be exceeded with pulsed patterns too long to be perceived as metrical units. This is a feature of James Tenney's KOAN, one of his Postal Pieces which have scores small enough to fit on post cards (Example 9). These pieces exhibit gradual, unidirectional formal processes and other proto-spectral features (Wannamaker 2008, 93-94), demonstrating Tenney's interest in "monolithic" forms that "do one thing and do it completely" and aspire to "elegance" in the sense that mathematicians use the term (Tenney; quoted in Dennehy 2008, 83). KOAN, a solo violin piece, is notated as a continuous, moderately slow tremolo, alternating between two adjacent strings, one of which is open (first D, then A, then E), and the other of which executes an extremely slow glissando (first $G$, then $D$, then $A$ ). The process begins with the perfect fifth on the $G$ and $D$ strings and ends with the open $\mathrm{E}$ and the note an octave above on the A string. The alternating pattern of the continuously changing dyad is certainly heard as a pulse (though its tempo is not notated precisely), but there are no cues implying higher-order accent patterns within the existence region for meter. Performing the piece on a string instrument requires the performer to change bow direction regularly, and Tenney instructs for this to happen every 8-10 note pairs: some listeners may hear this bow change as a weak indication of metric grouping, but if so this is the only feature of the music that remotely suggests metrical organization, and in my judgment the discontinuity of the changing bow is overwhelmed by the continuity of the dynamics and the glissando. Arrivals at perfect unisons, fifths, and the terminal octave are major structural events, standing out as "cadential" points following long periods of continually morphing microtonal dissonance: there are seven such "cadences" in the piece. The time between cadences varies between performances, but the instructions guarantee that they will be separated by time intervals far beyond the temporal thresholds of metrical units (the recordings I have heard separate them by c. 90-180s). The result is music with pulse but without meter.

(ii) Olivier Messiaen, “I. Liturgie de Cristal” (Quatuor Pour la Fin du Temps) (1941)

"eavesdropping on something everlasting" (Pople 1998, 18)

[44] From the perspective of auditory information processing, an important function of meter is to provide a simplified abstract framework that contextualizes more complicated surface rhythms: it is much easier to recognize, remember, and perform a complex rhythm if we can relate it to a simpler metrical pattern. It stands to reason that the greater the complexity of the metrical pattern, the lesser its utility in simplifying information. Accordingly, traditional Western music gravitates strongly towards simple metrical patterns: Huron states that about two thirds of meters that occur in Western classical music are duple, most of the remainder are triple or compound meters, and a mere $0.8 \%$ are more complex patterns (e.g., irregular or asymmetrical meters) (Huron 2006, 195). But even these more complicated meters are typically made up of units that fit within the perceptual present and subdivide into groups of two or three (e.g., $54=\underset{4}{2+3}$ or $\left.\begin{array}{c}3+2 \\ 4\end{array}\right)$, which can therefore still provide a contextual framework by which to interpret surface rhythms (albeit with somewhat more difficulty). Much more complex metrical patterns, of the sort that may challenge rather than enhance our rhythmic acuity, durational judgments, and physical entrainment, are very rare. However, where exceeding the auditory system's ability to process information is an aesthetic goal, as in some expressions of musical timelessness, excessive metrical complexity may be desirable: as Justin London postulates, “Messiaen's complexity is a means of pointing musically to 
transcendence. We are meant to be overwhelmed by the complexity of his music, not to grasp it" (London 2009, 66).

[45] "I. Liturgie de Cristal" from Quatuor Pour la Fin Du Temps superimposes four irregular periodic groupings, entrained to a common pulse and in precisely defined ratios (Example 10). This has the flavor of polymeter - which is already challenging (or, as some have argued, impossible) ${ }^{(13)}$ to resolve perceptually - but on a scale that reaches far beyond the limits of human entrainment or aural comprehension. The movement features a "double isorhythmic motet" between the piano and the cello that Sherlaw Johnson interprets "as symbolic of eternity (especially if one considers that it could then be subject to endless repetition)" (Johnson 1998, 127; quoted in Shenton 2008, 53). Of course, any cyclical pattern could theoretically be subject to endless repetition, but this particular pattern is remarkable in its scope and complexity. The piano superposes a sequence of 29 chords with a sequence of 17 durations for a total of 493 combinations. Simultaneously, the cello combines 5 harmonics with 15 durations (encompassing two nonretrogradable patterns) for a total of 75 combinations. The overall result is a compound pattern that would require about two hours to complete a single period (Linton 1998), yet the piece only lasts about three minutes.

[46] This construction is out of all proportion with the periodic structures associated with most metrical (or polymetrical) patterns, seemingly closer to diurnal cycles than to the perceptual present. Nevertheless, the individual patterns are at least potentially available to the listener. It may be unreasonable to expect a listener to memorize a sequence of 29 piano chords, but some level of awareness of the recurring harmonic pattern is likely, and the probability that they can internalize the cycle of 5 cello harmonics is very high. Likewise with the rhythmic patterns: memorization will probably not easily occur for most listeners, but recognition of recurring local patterns and extrapolation to a sense of larger-scale recurrence are more probable. In short, while it is highly unlikely that listeners will grasp the structure and scale of the overall process unfolding in the music, it is much more likely that they will recognize that a compound process of some kind is unfolding and that its complexity and scope are beyond their ability to grasp perceptually. In pointing (quite far in this instance) outside the human scale of human entrainment and auditory information processing, the temporal organization of this music may be perceived to express timelessness.

\section{Grouping}

[47] Other aspects of temporal organization that are harder to define in terms of perceptual threshold values are still highly relevant to musical time and timelessness. For example, the proportions of phrases and other musical groupings can have a powerful impact on the way we perceive musical time, as Wagner famously recognized in his concept of "endless melody" (Grey 1995). ${ }^{(14)}$ The limits of the perceptual present and short-term memory intuitively seem as relevant for groupings as they are for individual events. Up to a certain threshold the information is processed as a single percept, such that we are immediately aware of all of the elements in their original order, and after that threshold is crossed, additional cognitive resources are required to represent it as a single perceptual entity. However, there is some disparity between authors in the maximum proportions they allow for the perceptual representation of musical groupings. For example, Fraisse describes the limits of musical grouping synonymously with the limits of the perceptual present, which he sets at a maximum of approximately 5 to 10 seconds "under the most favourable conditions" $(1963,93)$, while Snyder discusses the limits of musical grouping in terms of the threshold between short-term and long-term memory, which he places at about 8-16 seconds, "about the length of a very long phrase" $(2000,193)$. Additionally, it seems plausible that the temporal extent of a grouping that can be retained as present in the mind may vary according to its content (for example, groupings that are very complex or information-dense may have smaller temporal limits than those that are very simple). These questions may provide fruitful directions for future research. Fortunately, the absence of a clear upper boundary does not change my analysis very much with respect to musical timelessness, because composers who seek to challenge our information-processing capacity with excessive grouping tend to do so with vastly excessive grouping. 
V. Excessive Grouping: Olivier Messiaen, (Quatuor Pour la Fin du Temps) (1941)

(i) "III. Abîme des Oiseaux"; (ii) "V. Louange à l'Éternité de Jésus,"; (iii) "VIII. Louange

à l'Immortalité de Jesus"

"the opposite of time" (Messiaen 1942); "an elongation of time" (Bell 1984, 60)

[48] In the clarinet solo movement "Abîme des Oiseaux" from Quatuor Pour la Fin du Temps (1941), Messiaen deliberately juxtaposes and contrasts two radically different temporalities. In the preface to the score, the composer writes:

The abyss is Time, with its sadness, its weariness. The birds are the opposite of Time: our desire for light, stars, rainbows, and jubilant vocalises! (Messiaen 1942)

The temporal abyss is characterized in sections with extremely slow tempi and lugubrious motion, very long silences, and almost superhuman durations and crescendi on single notes. The first notated phrase, for example, is 40 seconds in duration at the composer's notated tempo, and the longest single notes are over 10 seconds long. These proportions are vastly in excess of the normative durations of Western music: Snyder identifies three to five seconds as the average length of most sentences and musical phrases (Snyder 2000, 50), but here individual notes and rests exceed that range. In performance, many clarinettists extend these proportions even longer.

[49] "V. Louange à l'Éternité de Jésus" extends phrase duration to even greater extremes: in the preface, the composer describes the c. 9-minute movement as "one large phrase, infinitely slow, for the cello." At the notated tempo, the frequent quarter notes and half notes in the cello line are c. 5.6 seconds and 11.2 seconds, respectively, and the terminal dotted whole note is over 33 seconds in duration (Example 11). The piano accompaniment pattern also features extreme proportions of musical grouping. The tempo of the sixteenth-note is indicated as c. 44 BPM (c. 1.4s IOI). While very slow, it is still within the beat zone. However, the beamed notation implies that sixteenth-note iterations do not define the beat itself but rather the subdivisions of the beat: the pulse would be four times slower, quarter note $=11$ BPM (c. 5.6s IOI), well below the beat zone. It is therefore likely that listeners will choose the subdivision rather than the notated beat as their perceptual tactus, ${ }^{(15)}$ but this contradicts the ideal pulse Messiaen appears to imply from the notation. The harmonic prolongations created by repeated chords range from 1 to 26 iterations (c. 1.4-35s) with an average of about 6.5 (c. $9.2 \mathrm{~s}$ ), frequently pushing or exceeding the listener's capacity for musical grouping.

[50] "VIII. Louange à l'Immortalité de Jésus" is to be performed Extrêmement lent et tendre, extatique (extremely slow and tender, ecstatic). The tempo indication is eighth note = c. 36 BPM (c. 1.7s IOI), but the movement is notated in ${ }_{4}^{4}$ time so the notated pulse is actually quarter note = c. $18 \mathrm{BPM}$ (3.4s IOI), significantly slower than the lower limit of the beat zone. This movement's piano accompaniment consists of thirty-second double-dotted-eighth pairs. The two articulations of each pair will easily group together, with an IOI of c. $0.4 \mathrm{~s}$, but the c. 3s gap before the onset of the next pair is long enough to break up sequence perception. The repeated figures in the piano then take on the character of a series of events in groups of two, which appear as isolated rhythmic units rather than as a continuous sequence (although they are unified at another level by harmonic prolongation and sustained resonance). The violin phrases are extremely long, especially towards the end of the movement in which the violin's gradual ascent to its extreme high register expresses "the ascent of man towards God, of the child of God to the Father, of divine creation towards Heaven" (Messiaen 1942, preface; my translation). Luchese points out that Messiaen's slow movements, such as the two Louanges, are often described as "timeless" and "transcendent," conveying "an impression of changelessness" through the extreme slowness of pulse, low rhythmic density, and protracted harmonic rhythm (Luchese 2010, 179-82).

\section{Repetition}

[51] Any discussion of musical timelessness would be incomplete without mentioning the important role of repetition. In the history of Western music, perhaps no movement has been so consistently associated with the induction of psychological states as minimalism, due in large part to its employment of extreme repetition. Terms like "mystical," "narcotic," "entrancing," and 
"meditative" are common currency in minimalist discourse, and the experience of time and timelessness is among the most central of topics. The perceptual and psychological effects of repetition are difficult to discuss in terms of defined values, because they depend to a large extent on contextual factors such as the content of what is repeated, whether the repetition is exact or approximate, whether all musical parameters are repeated or only some, whether the repetition occurs immediately (proximal) or after intervening material (distal), how many times the material is repeated, and so forth. The type of repetition that is most often discussed in relation to the experience of musical timelessness, and the type on which this discussion will focus, is proximal repetition of short musical cells. These cells may remain exactly the same in subsequent statements or may vary subtly over time. Many authors seem to have found a certain magic in music so organized: Margulis describes the experience of listening as "entering into a kind of sympathy with the music" (Margulis 2013, 146); Fraser likens it to the "ecstasy of the dance ... an experience of timelessness, a radical decrease in existential tension" (Fraser 1975, 305); for Grisey it "seeks a state of trance by annihilating time" (Grisey 1987, 24).

[52] Grisey considered periodic repetition to be "the most simple, most probable phenomenon" that provided "an ideal point of reference for the perception of time," but also cautioned that "absolute, mechanical periodicity tires the listener . . . its perfect redundancy merely induces boredom and inattention" $(1987,245)$. The composers' intuitions have largely been borne out by empirical research, but there is some disagreement on the relation between repetition and expectation. Meyer claimed that repetition prompted an expectation for change, while Narmour claimed it invoked expectation of more of the same, leading Margulis to conclude that it is "simply too reductive to assert that repetition implies either continuation or change" (Margulis 2013, 24). Huron describes how accurate prediction is inherently and adaptively pleasurable (Huron 2006, 12-13), suggesting that since repetition increases predictability, it should also increase listening pleasure, but that when music becomes too predictable, it may become boring, irritating, and habituating $(2006,240)$. Marie Reiss Jones finds that although simple, repetitive rhythms are easier to recall $(1993,89)$, those stimuli will be most engaging that provide information patterned enough for us to form expectations but not so patterned that those expectations are satisfied every time $(2009,81-92)$. Attention will tend to be (1) heightened in those time zones in which patterns deviate slightly from their expected paths, (2) caught but lost quickly in zones whose expectations are fulfilled with perfect consistency (since it will seem pointless to continue forming expectations that have already been satisfied), and (3) minimized in zones that seem completely unpredictable or indecipherable (since it will seem pointless to form expectations in the absence of any reasonable likelihood that they will be satisfied) (Jones 1976, 345).

[53] Margulis notes that "repetition tends to reify a passage-to set it apart from the surrounding context as a "thing" to be mused on, abstractly considered, and conceptualized as a unit" (2013, 43). This tendency intensifies when the unit is repeated so obsessively that it becomes the context for its own interpretation. In most Western classical and popular musics, there are usually no more than two or three consecutive exact repetitions of a motive, phrase, or sequence. The listener is typically aware how many times they have heard a repeating pattern, except perhaps in cases such as chaconne, passacaglia, or ostinato in which a greater number of repetitions are continually recontextualized with changes elsewhere in the music. Proximally repetitive music presents a fundamentally different situation in which the listener may lose track of how many times they have heard a repeated cell; indeed, to try to count them would seem to miss the point of the music. The small size of the cells frequently used in this music - often a single measure or less, just a second or two in length-also has an important perceptual effect. Such small repeating units create an "intense impression, as if the music were bombarding you again and again from close proximity" (Margulis 2013, 44). The listener's expectations, focal parameters, and listening strategies tend to shift as the repeating cell becomes a new normal. Listeners accustomed to assuming (perhaps implicitly) that pitch and duration are the "primary" musical parameters may gradually shift their attention to subtleties of timbre, nuance, microstructure, and expressive timing (Margulis 2013, 59). If the texture is multi-layered, listeners may re-orient their listening perspective to focus now on one layer, now on another, now on relations between the two. The effect can be one of studying an object extended in time from many different perspectives, meditating on it, becoming intimately familiar with it. As Margulis notes, "nuanced objects are 
more compelling on repetition ... the thing is known, yet constantly rediscovered-never grasped - and this may result in a satisfying pull toward the present moment" (Margulis 2013, 18).

[54] In proximally repetitive music, segmentation, sequence, pulse, meter, and grouping may occur within their optimal human time scales, and yet this music is often described as timeless (or mesmerizing, hypnotic, trance-inducing, and so forth) (Quinn 2006, 284). This is likely because it invites listeners to adopt a non-normative, "non-directed" listening strategy "in which the listener is no longer submitted to the constraint of following the musical evolution" (Mertens 2017, 426). Instead of a mode of listening based on memory and prediction, the listener is free to experience the music as present, with even subtle changes taking on a heightened perceptual significance. However, in order for this type of listening to take effect, the music must maintain the listener's attention, and if the repetition is always exact our attention tends to wander before long.

Composers have been conscious of this: there are many examples of compositions that parsimoniously impart new information throughout extended passages of proximal repetition.

\section{Extreme Proximal Repetition: Gérard Grisey, Vortex Temporum I (1994-96)}

$$
\text { "I forgot to measure the time that was passing" (Hervé 2001,9) }
$$

[55] The first section of Grisey's Vortex Temporum I dances on the threshold between periodic regularity and irregularity (Hervé 2004, 18), presenting a steady stream of new information despite apparent extreme repetitiveness as the quoted Ravelian arpeggio is constantly reiterated throughout continual transformations. The section is made up of 43 phrases, each of which is composed from one or more of nine motivic cells which range from two to fourteen notes in length. (16) The cells in turn are composed from one or more of nine subcells, which range from two to four notes in length. Many of the subcells appear in more than one cell, many subcells of the same cardinality are related by retrograde or inversion, and many subcells of different cardinalities stand in subset relation, ${ }^{(17)}$ guaranteeing a high degree of motivic unity in spite of the large number of building blocks. Almost all of the phrases follow a decrescendo contour (though these vary in speed and dynamic range), and their durations all fit approximately within the boundaries of the perceptual present. No two phrases are identical in cellular composition, and only a few have equal durations. ${ }^{(18)}$ Examples 12a and 12b show the subcells and their relations to one another. Example 13 shows the construction of cells from subcells, as well as the period (in sixteenth notes) and time (in seconds) of each cell.

[56] Example 14 shows the construction of all of the phrases in this section from the cells, including the number of times each cell appears in the phrase (ext = extended, inc = incomplete), along with the phrases' periods, durations, registers, and dynamic contours. As noted above, no two phrases are identical in their cellular construction, and when pitch content and register are introduced into the equation as well, the variation multiplies even more. Example 15 annotates the phrase structure of the left-hand piano part, which provides a suitable reduction of the overall score in terms of the properties of interest to this discussion. The instruments function as a collective hyper-instrument rather than an ensemble of distinct individuals. The music presents itself as a unified auditory stream, immersing the listener in continuous transformation through extreme proximal repetition.

[57] At the beginning, in which cell I predominates for nearly 30 seconds with few surprises, a regular pulse is established with binary metrical organization and a pulse close to the indifference zone. After this initial acclimatization period, the changes become more and more frequent, and phrase durations diminish steadily (though non-linearly) to the end of the section. In other words, having acclimatized the listener to periodic regularity within an optimal scale for auditory information processing and entrainment, Grisey progressively increases the information density to prevent habituation and the ensuing risks of boredom or lost attention. This is just the kind of situation Jones described as most likely to hold attention: enough periodic recurrence to form expectations, but not so much that those expectations are satisfied every time. It may be to this meticulous organization of information and temporal proportions that the music owes the entrancing quality described by Hervé (2001) and Baillet (2000). It was certainly a preoccupation of Grisey's as he composed his temporal vortex. 
[58] 20th-century composers, including those cited above, have exploited (intuitively or deliberately) the temporal structure of auditory perception, creating music that pushes the limits of our capacities for segmentation, sequence perception, pulse entrainment, metrical complexity, grouping, and proximal repetition. The perceptual effects of these temporal excesses and subversions have attracted much interest among composers, theorists, and analysts, and they have frequently been described in terms of timelessness. The preceding examples were selected to demonstrate that such descriptions are not merely impressionistic or arbitrary, nor are they contingent on the induction of altered experiences of time in any given listener. The temporal organization of music helps define its fictional universe. That fiction may conform closely to human time, or may point outside of human time, to timelessness.

\section{Conclusion}

[59] The musical induction of an altered sense of time is familiar to many people. Passionate absorption in music is gloriously widespread among musicians and non-musicians alike, and equally glorious is the expansive range of musics, cultural contexts, and subjective orientations of listeners around the world that can lead to such profound personal experiences. In addition, some music may embody characteristics that point outside of human time in virtue of their observable, temporal properties, such that we may perceive the music to express timelessness regardless of whether or not an altered experience of time is actually induced in us when we listen. Such music seems to be about timelessness. Titles such as Vortex Temporum, Le Temps et l'Écume, Quatuor Pour la Fin $d u$ Temps, and Echoes of Time and the River (and more indirectly, Continuum, Atmosphères, and $K O A N$ ) suggest that timelessness has been a conscious preoccupation of many composers, and that interplay between the temporal organization of their music and the temporal structure of auditory perception is not accidental.

[60] In this paper, I have reviewed findings from the field of music perception and cognition related to the temporal structure of auditory perception, specifically dealing with segmentation, sequence, pulse, meter, grouping, and repetition. For some of these categories, I have provided ranges and threshold values characterizing our qualitative experiences of auditory phenomena, based on extant empirical research. I have suggested that these values help define human time, a temporal scale and structure of optimal embodiment and auditory information processing by humans. Music presents temporal fictions by organizing sound in self-contained universes that may conform closely to human time (by presenting information optimally suited for comprehension and mimetic participation) or may depart from it to varying degrees (by subverting or exceeding one or more of its temporal parameters). Music that takes this second path points outside of our normative temporal experience, and thus, adopting J. T. Fraser's (1975) broad definition presented in the introduction, may be perceived as expressing timelessness. However, as stressed above, both the body of empirical research that grounds our understanding of temporal auditory perception and the musical culture that contextualizes this study are thoroughly Western, and it remains unclear to what extent (if at all) the claims made here can be generalized to other cultures. The compositions examined in this paper are all pieces of Western music from the 20th century, but many of these draw inspiration from non-Western practices. It may be that the expression of timelessness in Western music is predicated on a culturally relative "otherness." Since both musical practices and philosophical ideas about time vary considerably between cultures, it seems highly plausible that at least some of the claims made above may be culturespecific. Therefore, they should not be generalized without further, cross-cultural study.

[61] I see great promise in combining music perception and cognition research with musictheoretical and musicological inquiry, as I have tried to do in this paper. Nevertheless, the study has limitations. With respect to the question of musical timelessness, there remain many other potentially relevant factors that should be explored in greater detail: for example, timbre, resonance, ritual, and visual/kinaesthetic elements of performance may all be important factors that deserve dedicated study. I have used the umbrella term "timelessness" to refer to all nonnormative scales and structures of time, but in many cases finer distinctions may be warranted. I 
have not carried out original empirical studies on the esthesics of timelessness to determine to what extent people's experiences of this music reflect the theoretical descriptions reported here. All of these lacunae should be pursued in future research, which should bring together philosophical, scientific, and artistic perspectives.

[62] While preparing this paper, I frequently listened to the cited examples as I worked. At times I would put my writing away and attend closely to what I was hearing, sometimes following the score. The music, when given my full attention, seemed immersive, enchanting, mesmerizing. On a different day, perhaps even later on the same day, that same music might come around again on my playlist, and due to my attention being preoccupied elsewhere, I would only vaguely be aware of it in the background, with little effect on my state of mind. Another, concluding anecdote: during the preparation of this paper, legendary Canadian rock band The Tragically Hip, whose music is the virtual antithesis of the types of music discussed in this paper, performed their farewell concert a few weeks after lead singer Gord Downie had been diagnosed with brain cancer (which took his life some months later). Watching the live stream of the concert, I was overwhelmed with emotion, reliving a lifetime of experiences for which their songs had been the soundtrack, and for that extended moment it was as if time stood still.

Jason D. K. Noble

McGill University, Schulich School of Music

Music Perception and Cognition Lab

Centre for Interdisciplinary Research in Music Media and Technology

555 Sherbrooke St. W

Montreal, Quebec, Canada

H3A 1 E3

jason.noble@mcgill.ca

\section{Works Cited}

Adorno, Theodor. 2006. Philosophy of New Music. Translated by Robert Hullot-Kentor. University of Minnesota Press.

Augustine, Saint. 1860. The Confessions of S. Augustine. Edited, with an introduction by William G. T. Shedd. Andover.

Baillet, Jérome. 2000. Gérard Grisey: Fondements d'une écriture. L'Itinéraire.

Bauer, Amy. 2004. "'Tone-color, Movement, Changing Harmonic Planes': Cognition, Constraints and Conceptual Blends in Modernist Music." In The Pleasure of Modernist Music: Listening, Meaning, Intention, Ideology, ed. Arved Mark Ashby, 121-52. University of Rochester Press.

Becker, Judith. 2004. Deep Listeners: Music, Emotion, and Trancing. Indiana University Press.

Bell, Carla. 1984. Olivier Messiaen. Twayne Publishers.

Born, Georgina. 2015. "Making Time: Temporality, History, and the Cultural Object." New Literary History 46 (3): 361-86.

Cohen-Levinas, Danielle, ed. 2005. Le Temps de L'Écoute: Gérard Grisey, ou la beauté des ombres sonores. L'Itinéraire.

Chen, Huey-Meei. 2010. Temporality and Process in the Compositions of Gérard Grisey. Ph.D. diss., Columbia University.

Chen, Joyce Lynn. 2008. “The Neural Basis for Auditory-Motor Interactions during Musical Rhythm Processing." Ph.D. diss., McGill University.

Cox, Arnie. 2016. Music E Embodied Cognition: Listening, Moving, Feeling, E Thinking. Indiana University Press. 
Cox, Cristoph. 2017. "Minimalisms: Introduction." In Audio Culture: Readings in Modern Music, Rev. ed., ed. Cristoph Cox and Daniel Warner, 417-418. Bloomsbury.

Dennehy, Donnacha. 2008. “Interview with James Tenney.” Contemporary Music Review 27 (1): 79-89.

Douglas, Chelsea, Jason Noble, and Stephen McAdams. 2016. "Auditory Scene Analysis and the Perception of Sound Mass in Ligeti's Continuum." Music Perception 33 (3): 287-305.

Epstein, Paul. 1986. "Pattern Structure and Process in Steve Reich's 'Piano Phase."” The Musical Quarterly 72 (4): 494-502.

Fraisse, Paul. 1963. The Psychology of Time. Translated by Jennifer Leith. Harper \& Row.

Fraser, J. T. 1975. Of Time, Passion, and Knowledge: Reflections on the Strategy of Existence. G. Braziller.

Gabrielsson, Alf. 2001-2002. “Emotion Perceived and Emotion Felt: Same or Different?" Musica Scientiae 5 (1): 123-47.

Gibson, J. J. 1975. “Events are Perceivable but Time is Not." In The Study of Time II: Proceedings of the Second Conference of the International Society for the Study of Time, Lake Yamanaka, Japan, ed. J. T. Fraser and N. Lawrence, 295-301. Springer-Verlag.

Grahn, Jessica. 2012. “Neural Mechanisms of Rhythm Perception: Current Findings and Future Perspectives." Topics in Cognitive Science 4: 585-606.

. 2017. "Moving and Grooving: Rhythm, Movement, and the Brain." Keynote address at the Conference of the Society for Music Perception and Cognition, San Diego, CA, 30 July, 2017.

Grey, Thomas. 1995. Wagner's Musical Prose: Texts and Contexts. Cambridge University Press.

Grisey, Gérard. 1982. “La musique: Le devenir des sons.” Darmstädter Beiträge zur Neuen Musik 19: 4556.

1987. “Tempus ex Machina: A Composer's Reflections on Musical Time.” Contemporary Music Review 2 (1): 239-75.

. 1996. “Vortex Temporum I, II, III (1994-1996): Program Notes.” IRCAM. Accessed 28

August 2018. http://brahms.ircam.fr/works/work/8977/

2008a. Écrits ou l'Invention de la Musique Spectrale. Edited by Guy Lelong. MF Éditions.

Hasty, Christopher. 1986. "On the Problem of Succession and Continuity in Twentieth-Century Music." Music Theory Spectrum 8 (1): 58-74.

1997. Meter as Rhythm. Oxford University Press.

Heikenheimo, Seppo. 1972. The Electronic Music of Karlheinz Stockhausen: Studies on the Esthetical and Formal Problems of its First Phase. Suomen Musiikkitieteellinen Seura.

Hellmuth, Mara. 2006. “Barry Truax's Riverrun.” In Analytical Methods of Electroacoustic Music, ed. Mary Simoni, 187-238. Routledge.

Henrich, Joseph, Steven J. Heine, and Ara Norenzayan. 2010. "The Weirdest People in the World?" Behavioral and Brain Sciences 33: 61-135.

Henry, Molly. 2016. "The Neural Dynamics of Sensing a Beat." Presentation, McGill Cognitive Seminar, McGill University, Montreal, QC, 11 March 2016.

Hervé, Jean-Luc. 2001. Dans le Vertige de la Durée: Vortex Temporum de Gérard Grisey. L'Itinéraire.

2004. "Formes et temporalités dans les dernières œuvres de Gérard Grisey." In Le Temps

de l'Écoute: Gérard Grisey, ou la beauté des ombres sonores, ed. Danielle Cohen-Levinas, 15-22.

L'Harmattan. 
Huron, David. 2001. "Tone and Voice: A Derivation of the Rules of Voice-Leading from Perceptual Principles." Music Perception 19 (1): 1-64.

2006. Sweet Anticipation: Music and the Psychology of Expectation. MIT Press.

Janata, Petr, Stefan T. Tomic, and Jason M. Haberman. 2012. "Sensorimotor Coupling in Music and the Psychology of the Groove." Journal of Experimental Psychology: General 141 (1): 54-75.

Johnson, Sherlaw. 1998. "Rhythmic Technique and Symbolism in the Music of Olivier Messiaen." In Messiaen's Language of Mystical Love, ed. Siglind Bruhn, 121-40. Garland.

Jones, Mari Riess and William Yee. 1993. "Attending to Auditory Events: The Role of Temporal Organization." In Thinking in Sound: The Cognitive Psychology of Human Audition, ed. Stephen McAdams and Emmanuel Bigand, 69-112. Oxford University Press.

Jones, Mari Riess. 1976. "Time, Our Lost Dimension: Toward a New Theory of Perception, Attention, and Memory." Psychological Review 83 (5): 323-55.

_. 2009. "Musical time." In Oxford handbook of music psychology, ed. Susan Hallam, Ian Cross and Michael Thaut, 81-92. Oxford University Press.

Juslin, Patrik and Petri Laukka. 2004. "Expression, Perception, and Induction of Musical Emotions: A Review and Questionnaire Study of Everyday Listening." Journal of New Music Research 33 (3): 21738.

Knowles, Kristina. 2016. The Boundaries of Meter and the Subjective Experience of Time in Post-tonal, Unmetered Music. PhD diss., Northwestern University.

Kramer, Jonathan. 1988. The Time of Music: New Meanings, New Temporalities, New Listening Strategies. Schirmer.

Klein, Michael. 2004. “Chopin's Fourth Ballade as Musical Narrative.” Music Theory Spectrum 26 (1): 23-56.

Large, Edward. 2015. "President's Address." Presentation, Conference of the Society for Music Perception and Cognition, Vanderbilt University, Nashville TN, 03 August 2015.

Large, Edward, Jorge Herrera, and Marc Velasco. 2015. “Neural Networks for Beat Perception in Musical Rhythm." Frontiers in Systems Neuroscience 25: 1-14.

Lehman, Stephen. 2012. "Liminality as a Framework for Composition: Rhythmic Thresholds, Spectral Harmonies and Afrological Improvisation." DMA diss., Columbia University.

Ligeti, György. 1988 “On My Piano Concerto.” Translated by Robert Cogan. Sonus 9 (1): 8-13.

Ligeti, György et al. 1983. Ligeti in Conversation. Eulenburg.

Linton, Michael. 1998. "Music for the End of Time." First Things. Accessed 16 July 2013. http://www.firstthings.com/article/1998/11/004-music-for-the-end-of-time

Lochhead, Judy. 1982. “The Temporal Structure of Recent Music: A Phenomenological Investigation.” PhD diss., State University of New York at Stony Brook.

\footnotetext{
93.
}

London, Justin. 2004. Hearing in Time: Psychological Aspects of Musical Meter. Oxford University Press.

\footnotetext{
- 2009. "Temporal Complexity in Modern and Post-Modern Music: A Critique from Cognitive Aesthetics." In Unfolding Time: Studies in Temporality in Twentieth Century Music, 45-68. Leuven University Press.
} 
Luchese, Diane. 2010. “Olivier Messiaen's Slow Music: A Reflection of Eternity.” In Olivier Messiaen: The Centenary Papers, ed. Judith Crispin, 179-92. Cambridge Scholars Publishing.

Margulis, Elizabeth. 2013. On Repeat: How Music Plays the Mind. Oxford University Press.

McAdams, Stephen. 2016. “Time, Rhythm and Meter Perception." Lecture in MUMT 250: Music Perception and Cognition, McGill University, Montréal, QC, February 2016.

Mertens, Wim. 2017. "Basic Concepts of Minimal Music." In Audio Culture: Readings in Modern Music, Rev. ed., ed. Christoph Cox and Daniel Warner, 425-430. Bloomsbury.

Messiaen, Olivier. 1966. The Technique of my Musical Language. Translated by John Satterfield. Alfonse Leduc.

Michon, J. A. 1978. “The Making of the Present: A Tutorial Review." In Attention and Performance VII, ed. J. Requin, 89-111. Lawrence Erlbaum.

Molino, Jean. 1975. “Fait musical et sémiologie de la musique.” Musique en Jeu 17: 37-62.

Monelle, Raymond. 2000. The Sense of Music. Princeton University Press.

Nattiez, Jean Jacques. 1990. Music and Discourse: Toward a Semiology of Music. Translated by Carolyn Abbate. Princeton University Press.

Oliveros, Pauline. 2005. Deep Listening: A Composer's Sound Practice. iUniverse, Inc..

Parncutt, Richard. 1994. "A Perceptual Model of Pulse Salience and Metrical Accent in Musical Rhythms." Music Perception 11 (4): 409-64.

Plack, Christopher. 2014. The Sense of Hearing. 2nd ed. Psychology Press.

Pople, Anthony. 1998. Messiaen: Quatuor pour la fin du Temps. Cambridge University Press.

Povel, Dirk-Jan and Peter Essens. 1985. "The Perception of Temporal Patterns." Music Perception 2: 411-40.

Quinn, Ian. 2006. "Minimal Challenges: Process Music and the Uses of Formalist Analysis." Contemporary Music Review 25 (3): 283-94.

Reiner, Thomas. 2000. Semiotics of Musical Time. Peter Lang.

Repp, Bruno. 2005. "Sensorimotor Synchronization: A Review of the Tapping Literature." Psychonomic Bulletin and Review 12: 969-92.

Roads, Curtis. 2001. Microsound. MIT Press.

2003. "The Perception of Microsound and Its Musical Implications." Annals of the New York Academy of Sciences 999 (1): 272-81.

Rouget, Gilbert. 1980. La Musique et la transe: Esquisse d'une théorie générale des relations de la musique et de la possession. Gallimard.

Sandstrom, Gillian and Frank Russo. 2011. "Absorption in Music: Development of a Scale to Identify Individuals with Strong Emotional Responses to Music." Psychology of Music 41 (2): 216-28.

Shenton, Andrew. 2008. Olivier Messiaen's System of Signs. Ashgate.

Snyder, Bob. 2000. Music and Memory. MIT Press.

Stockhausen, Karlheinz. 1963. Text zur elektronischen und instrumentalen Musik I: Aufsätze 1952-1962 zur

Theorie des Komponierens. Edited by Dieter Schnebel. Verlag M. DuMont Schauberg.

Sylvan, Robin. 2005. Trance Formation: The Spiritual and Religious Dimensions of Global Rave Culture.

Routledge. 
Taylor, Benedict. 2010. “On Time and Eternity in Messiaen.” In Olivier Messiaen: The Centenary Papers, ed. Judith Crispin, 256-80. Cambridge Scholars Publishing.

Tenney, James. 1978. “Gayle Young interviews James Tenney.” Only Paper Today 5 (5): 4.

Tierney, Adam and Nina Kraus. 2014. "Neural Entrainment to the Rhythmic Structure of Music." Journal of Cognitive Neuroscience 27 (2): 400-408.

Toivianen, Petri, Geoff Luck, and Marc R. Thompson. 2010. “Embodied Meter: Hierarchical Eigenmodes in Music-Induced Movement." Music Perception 28 (1): 59-70.

Truax, Barry. 1988. "Real-time Granular Synthesis with a Digital Signal Processor." Computer Music Journal 12 (2): 14-26.

$120-34$

Wannamaker, Robert. 2008. “The Spectral Music of James Tenney.” Contemporary Music Review 27 (1): 91-130.

\section{Scores}

Crumb, George. 1968. Echoes of Time and the River. Belwin-Mills.

Grisey, Gérard. 1993. Le Temps et l'Écume. Milano: Ricordi. 1998. Vortex Temporum. Italy: Ricordi.

Ligeti, György. 1963. Atmosphères. Vienna: Universal Edition. 1970. Continuum. Mainz: B. Schott's Söhne.

Messiaen, Olivier. 1942. Quatuor pour la Fin du Temps. Paris: Durand.

Reich, Steven. 1980. Piano Phase. London: Universal Edition.

Tenney, James. 1984. Postal Pieces. Baltimore: Sonic Art Editions.

\section{Discography}

Crumb, George. 2006. Echoes of Time and the River. Warsaw Philharmonic Orchestra, conducted by Thomas Conlin. On Complete Crumb Edition, Vol. 6. Bridge Records. CD.

Grisey, Gérard. 2001. Vortex Temporum. Ensemble Recherche. On Vortex Temporum; Talea. Accord. CD. . 2008b. Le Temps et l'Écume. WDR Sinfonieorchester Köln, conducted by Emilio Pomárico. On Le Temps et l'Écume; Les Chants de l'Amour. Kairos. CD.

Kennedy, John. 2002. Liner notes, Variazioni; Echoes of Time and the River. Performed by Louisville Orchestra conducted by Jorge Mester. First Edition Music. CD.

Lange, Art. 1999. "A Reconstruction of Classicism." Liner notes, James Tenney Music for Violin E Piano performed by Marc Sabat and Stephen Clarke. Hat Hut Records. CD.

Ligeti, György. 1994. Atmosphères. Berliner Philharmoniker, conducted by Jonathan Nott. On The Ligeti Project II. EMI Classics. CD.

— 1997. Continuum. Elisabeth Chojnacka. On György Ligeti: Keyboard Works. Sony Classical. CD.

Messiaen, Olivier. 2017. Quatuor pour la Fin du Temps. Martin Fröst, Lucas Debargue, Janine Jansen, Torleif Thedéen. Sony Classical. CD. 
Reich, Steven. 1987. Piano Phase. Nurit Tilles and Edmund Niemann. On Steve Reich: Early Works. Elektra/Nonesuch. CD.

Tenney, James. 2007. Postal Pieces. Barton Workshop conducted by James Fulkerson. New York: DRAM. CD.

Truax, Barry. 1987. Riverrun. On Digital Soundscapes. Cambridge Street Records. CD.

\section{Videography}

Kubrick, Stanley, dir. 2001. 2001: A Space Odyssey. 1968; Burbank, CA: Warner Home Video. DVD.

Reggio, Godfrey, dir. 2002. Koyaanisqatsi. 1982; San Francisco, CA: American Zoetrope. DVD.

Snyder, Zack, dir. 2007. 300. 2006; Burbank, CA: Warner Home Video. DVD.

Wachowski, Andy, and Larry Wachowski, dirs. 2001. The Matrix. 1999; Burbank, CA: Warner Home Video. DVD.

\section{Footnotes}

* Thanks to Max Henry, who helped prepare the audio files. Thanks to Dr. Stephen McAdams and the members of the Music Perception and Cognition Lab at McGill University for valuable discussions during the preparation of this paper. Thanks to the Social Sciences and Humanities Research Council, Canada (SSHRC) for financial support during this project. Return to text

1. The proposed account is not intended as a universal explanation for all expressions of musical timelessness. It would not easily explain the timeless associations of Gregorian Chant, for instance (see Reiner 2000, 107).

Return to text

2. See, for instance, Juslin and Laukka 2004; Gabrielsson 2001-2002.

Return to text

3. Like many terms relevant to this discussion, "temporality" appears in the literature with a variety of differing senses. My use of the term is closer to Raymond Monelle's "cultural time," which encompasses "the time [music] may mean" (2000, 81-83), and the complex lived experiences of time for which Jonathan Kramer says music may stand as a metaphor $(1988,4-17)$, than to Judy Lochhead's mensural relations in the absence of a background structure (1986, 49-93).

Return to text

4. See, for example, Large, Herrera, and Velasco 2015; Tierney and Kraus 2014; Grahn 2012; London 2004; Povel and Essens 1985.

Return to text

5. See, for example, Born 2015; Cohen-Levinas 2005; Becker 2004; Monelle 2000; Kramer 1988;

Fraser 1975.

Return to text

6. Information (like time) is a notoriously difficult concept to define comprehensively, and it is beyond the scope of this paper to attempt to do so. It is assumed that the reader has an approximate sense of what the term denotes, in spite of the epistemological, logical, and philosophical quagmires that seem to ensnare any attempt to articulate it precisely. Bob Snyder's equation of information with novelty $(2000,209)$, while not without its problems, is close enough to suffice for my purposes, provided that "novelty" is understood to denote what is recognized as new in the subjective context of a given act of listening.

Return to text 
7. While this value has received considerable currency in the literature-see, for instance, Roads 2003, 275; Truax 1988, 18; Grisey 1982, 49-it is not an absolute value but covaries with sonic parameters, including register, timbre, and pitch organization. See Douglas, Noble, and McAdams 2016.

Return to text

8. J. A. Michon defines the perceptual present as "the time interval in which sensory information, internal processing, and concurrent behavior appear to be integrated within the same span of attention" (1978, 89; quoted in Lehman 2012, 14). See also Knowles 2016, 92-93; London 2004, $30-$ 31; Fraisse 1963, 84-85.

Return to text

9. Precise values for these windows vary between studies; these figures are from Snyder 2000, 25. Return to text

10. London identifies the "trill threshold," which he describes as the "point where the individual notes begin to blur," at around 10 notes per second $(2009,48)$.

Return to text

11. For example, Messiaen's modes of limited transposition (which, like his non-retrogradable rhythms, manifest "the charm of impossibilities"; Messiaen 1966, 8), timbres such as the complex inharmonic spectra of metallic idiophones like gongs and church bells, and the role of dynamic sustain in perceptual continuity are all likely associated with timelessness, and merit further investigation.

Return to text

12. The notated rests in this case do not correspond with actual silences, as the percussion instruments continue to resonate. Nevertheless, the rests produce greatly protracted IOIs that interrupt sequence integration.

Return to text

13. See, for instance, London 2004, 83.

Return to text

14. The phrase in which Wagner introduces this term likens "endless melody" to "sounding silence," another term that would seem to poetically resonate with the concept of musical timelessness.

Return to text

15. "A given piece of music usually implies a number of possible pulses, with different but closely related (e.g. 2:1, 3:1, 4:1) tempos. From these, listeners unconsciously choose one tempo that acts as a central framework in relation to which all the other tempos and rhythms are organized." Snyder 2000, 168.

Return to text

16. The pitch intervals of these cells are not absolute, so they are presented here in terms of rhythm and contour only.

Return to text

17. Although (viii) is a subset of (v) and (ix) is a subset of (iv) in terms of contour alone, the twonote groups begin on an accent whereas their counterparts in the four-note groups do not. This difference was considered perceptually significant enough to not consider these groups to stand in subset relations.

Return to text

18. 8 and 16, and 17 and 24 have the same duration and cellular structure but appear in a different register; 11 and 31, 18 and 20, 21 and 28, and 29 and 36 have the same duration but a different cellular structure; and 23 and 43 have the same duration but nothing else in common.

Return to text 


\section{Copyright Statement}

Copyright $\odot 2018$ by the Society for Music Theory. All rights reserved.

[1] Copyrights for individual items published in Music Theory Online (MTO) are held by their authors. Items appearing in MTO may be saved and stored in electronic or paper form, and may be shared among individuals for purposes of scholarly research or discussion, but may not be republished in any form, electronic or print, without prior, written permission from the author(s), and advance notification of the editors of MTO.

[2] Any redistributed form of items published in MTO must include the following information in a form appropriate to the medium in which the items are to appear:

This item appeared in Music Theory Online in [VOLUME \#, ISSUE \#] on [DAY/MONTH/YEAR]. It was authored by [FULL NAME, EMAIL ADDRESS], with whose written permission it is reprinted here.

[3] Libraries may archive issues of MTO in electronic or paper form for public access so long as each issue is stored in its entirety, and no access fee is charged. Exceptions to these requirements must be approved in writing by the editors of MTO, who will act in accordance with the decisions of the Society for Music Theory.

This document and all portions thereof are protected by U.S. and international copyright laws. Material contained herein may be copied and/or distributed for research purposes only. 